\title{
Comparing the efficacy of three diagnostic tools (microscopic examination, conventional PCR, and Real-Time PCR) in detecting Theileria equi infection among Egyptian equines
}

Ahmed M. Soliman ( $\nabla$ ahmed.mahmoud8933@yahoo.com )

Animal Health Research Institute https://orcid.org/0000-0002-3657-4781

Moaz M. Amer

Animal Health Research Institute

Fareed Uddin Memon

college of Animal Science and Technology, Guangxi University

\section{Research Article}

Keywords: T. equi, equine theileriosis, PCR, qPCR, microscopic examination, Egypt

Posted Date: August 2nd, 2021

DOl: https://doi.org/10.21203/rs.3.rs-770255/v1

License: (1) (i) This work is licensed under a Creative Commons Attribution 4.0 International License. Read Full License 


\section{Abstract}

Equine theileriosis represents one of the main and serious health problems affecting equines industry globally, that is caused by tick-borne protozoan parasite called $T$. equi. This study aimed to assess the sensitivity of three diagnostic tools named: microscopic examination of a blood smear, conventional PCR, and Real-Time PCR ( $\mathrm{PPCR})$ to detect $T$. equi among equine population $(n=116)$ raised in Giza Governorate, Egypt. Microscopic examination of Giemsa-stained blood smears revealed the infection of $16.4 \%$ (19/116) of examined equines by T. equi while conventional PCR and qPCR revealed that $29.3 \%$ (34/116) and $43.1 \%(50 / 116)$ of examined equines were infected with $T$. equi respectively. Our results demonstrated that the qPCR had the highest sensitivity (100\%) followed by conventional PCR (68\%) while microscopic examination had the lowest sensitivity (38\%). Furthermore, the negative predictive value (NPV) of qPCR was the highest (100\%) compared to conventional PCR and microscopical examination ( $80.49 \%$ and $68.04 \%$ respectively) which revealed that all negative cases detected by qPCR were certainly correct compared to the other two diagnostic assays. Therefore, it is highly recommended to incorporate PCR diagnostic assays (conventional PCR and qPCR) alongside microscopic examination to evaluate the epidemiological status of equine theileriosis.

\section{Introduction}

Globally, the equine industry suffers from a tick-borne protozoan parasite named Theileria equi (T. equi). This parasite has endemicity in tropical, subtropical and some temperate zones of the globe (Ozubek \& Aktas, 2018; Souza et al., 2019). Several tick vectors can transmit $T$. equi, the most vectors are those belonging to genera Dermacentor, Boophilus, Rhipicephalus, and Hyalomma whose distribution have a direct relation to the prevalence of $T$. equi (Bhagwan et al., 2015). Economically, T. equi has a significant effect on equine causing severe economic losses with impairment of equine movement. Equine theilerioses has several nonspecific symptoms such as anemia, icterus, edema, loss of condition, and even death. Survived animals remain carriers with low parasitemia for their lifetime thus representing a potential source of infection to surroundings (Malekifard et al., 2014; Mahmoud et al.,2016).

The standard technique for diagnosis of acute equine theilerioses is the microscopic examination of stained blood smears but due to low parasitemia in carrier animals, it is of low sensitivity (Kim et al.,2008; Elseify et al., 2018). Molecular methods are proved to have the highest specificity and sensitivity in the recognition of parasitic DNA. Polymerase chain reaction (PCR) can encounter parasitic nucleic acid in carriers with a parasitemia of $0.000001 \%$ (Alhassan et al., 2005; Davitkov et al 216).

This study aimed to detect the prevalence of $T$. equi among equines from Giza province, Egypt by microscopic examination of Giemsa-stained blood smear, conventional PCR, and Real-Time PCR (qPCR) and to differentiate between the sensitivity of these methods of diagnosis in the detection of $T$. equi.

\section{Materials And Methods}




\section{Animals and sample collection}

We collected 116 blood samples by jugular venipuncture method using EDTA tubes from equines reared in Giza Governorate, Egypt during the first semester of the year 2019. All collected samples were transferred to Animal Health Research Institute (AHRI) Dokki, Egypt for examination.

\section{Microscopic examination}

Giemsa-stained thin blood films were prepared from the collected whole blood and were inspected with a light microscope using an oil immersion lens (100X) for observation of intraerythrocytic merozoites belonging to $T$. equi according to (Levine, 1982).

\section{Molecular examination}

\section{DNA extraction}

Genomic DNA was isolated from all microscopically positive and negative samples using Thermo Scientific ${ }^{\text {TM }}$ GeneJET Genomic DNA Purification Kit (Cat No \#K0722) according to the manufacturer's instruction. The resulted DNA was preserved at $-80^{\circ} \mathrm{C}$ till used in the downstream examination.

\section{Conventional PCR}

PCR technique was performed using specific primers for T. equi, (Bec-UF2) F, 5-

TCGAAGACGATCAGATACCGTCG-3 and (Equi-R) R, 5-TGCCTTAAACTTCCTTGCGAT-3 established by (Alhassan et al., 2005). PCR reactions were performed using GoTaq ${ }^{\circledR}$ G2 Flexi PCR Kit (Promega, USA) with a total volume of $25 \mu$ l containing $5 X$ Green GoTaq ${ }^{\circledR}$ Flexi Buffer $(10 \mu \mathrm{l}), 25 \mathrm{mM} \mathrm{MgCl} 2$ Solution $(2$ $\mu \mathrm{l})$, PCR Nucleotide Mix (dNTPs) $10 \mathrm{mM}$ each $(1 \mu \mathrm{l})$, Primer mix $10 \mathrm{pmol}(1 \mu \mathrm{l}), 1.25 \mathrm{u}$ GoTaq®G2 Flexi DNA Polymerase template DNA $(5 \mu \mathrm{l})$, DNase/RNase free water $(6 \mu \mathrm{l})$. The thermal condition was 950C for $5 \mathrm{~min}$, followed by 35 cycles repeated of denaturation at $960 \mathrm{C}$ for $1 \mathrm{~min}$, annealing at $600 \mathrm{C}$ for $1 \mathrm{~min}$, and extension at $720 \mathrm{C}$ for $1 \mathrm{~min}$. then a final extension at $720 \mathrm{C}$ for $5 \mathrm{~min}$, after that holding stage at $40 \mathrm{C}$ for infinite time. $1.5 \%$ ethidium bromide-stained agarose gel was prepared. After that $8 \mu$ of the generated PCR products were loaded in it and allowed to migrate under constant volt of $80 \mathrm{~V}$ for $40 \mathrm{~min}$. visualization of agarose gel by Gel documentation system (XR) (Bio-Rad.UK). positive samples for T. equi showed a band of molecular weight of $392 \mathrm{bp}$ that were compared to a positive control sample obtained from the National Research Center (NRC), Egypt.

\section{Real-Time PCR (qPCR)}

The qPCR technique was accomplished conferring to (Kim et al., 2008) using specific primer and probe targeted 18s rRNA gene of T. equi, (Be18SF) a forward primer with a sequence 5GCGGTGTTTCGGTGATTCATA-3, (Be18SR) a reverse primer with a sequence 5TGATAGGTCAGAAACTTGAATGATACATC-3 and (Be18SP) a fluorescent TaqMan probe with a sequence 5AAATTAGCGAATCGCATGGCTT-3 that was labeled at its 5- end with a 6-carboxyfluorescein reporter dye and at 3-end with 6-carboxy-tetramethylrhodamine quencher dye. 
The qPCR 20 ul reaction consists of 4 ul Mix stable qPCR $5 x, 1 \mu l$ T. equi detec-qPCR mix, $5 \mu$ DNA template and $10 \mu \mathrm{l}$ nuclease free water. The qPCR was executed in a 96-well optical plate (Stratagene Mx3005 P) following this thermal profile: Activation at $95^{\circ} \mathrm{C}$ for $15 \mathrm{~min}$, followed by 45 cycles repeated of denaturation at $95^{\circ} \mathrm{C}$ for $20 \mathrm{sec}$, hybridization, extension and data collection at $55^{\circ} \mathrm{C}$ for $1 \mathrm{~min}$.

\section{Statistical Analysis}

Results were compared by one-way analysis of variance. Differences were determined by Fischer's least square difference test. The obtained results of the microscope, PCR, and qPCR were compared by using the $x 2$ test. All significant alterations were detected by a $p$-value $<0.05$.

Assessment parameters include specificity, sensitivity, likelihood ratio, positive predictive value (PPV) and negative predictive value (NPV) (Thrusfield, 2005).

\section{Results}

By microscopic examination, T. equi appeared as small single round, double round, single pyriform and maltase cross shapes (Figure. 1). While, by conventional PCR, the PCR product of T. equi were $392 \mathrm{bp}$ (Figure. 2) and by qPCR, the samples were considered positive when they displayed a positive FAM signals, on the other side were considered negative when they displayed a negative FAM signals. Positive results were represented by S-shape amplification curve. The inter section point between amplification curve and the threshold line called cycle threshold (Ct). Ct of our positive samples were ranged from 20 to 35 (Figure. 3).

Examination of Giemsa-stained blood smears confirmed the T. equi infection among equines in 19 (16.4\%) while conventional PCR showed 34 (29.3\%) and qPCR presented 50 (43.1\%). So, qPCR results are significantly higher than that of conventional PCR and microscopic examination as illustrated in (Table 1).

Table 1

Infection rate of $T$. equi among equines by microscopic examination, conventional PCR and qPCR.

\begin{tabular}{|lcc|}
\hline Techniques & Number of infected samples & $\%$ \\
\hline Microscope & $19 / 116^{\mathrm{C}}$ & 16.4 \\
\hline Conventional PCR & $34 / 116^{\mathrm{b}}$ & 29.3 \\
\hline Real time PCR (qPCR) & $50 / 116^{\mathrm{a}}$ & 43.1 \\
\hline $\begin{array}{l}\text { Data is presented as samples. total infected samples/total number of samples and total percent of } \\
\text { infected. Present superscript letters }\left({ }^{\mathrm{a}-\mathrm{c}}\right) \text { differ significantly. }\end{array}$ \\
\hline
\end{tabular}

Assessment parameters include specificity, sensitivity, negative predictive value (NPV) and positive predictive value (PPV) are illustrated in (Table 2 ) that showed (100\%) specificity for all used 3 methods 
for diagnosis but qPCR had the highest sensitivity (100\%) over conventional PCR (68 \%) and microscopical examination (38 \%). Likelihood Ratio results are illustrated in (Table 3 ).

Table 2

Assessment of Giemsa-stained blood smears, Conventional PCR and qPCR for detection of Theileria equi amongst Equines.

\begin{tabular}{|lccccccccc|}
\hline Techniques & Total & TP & TN & FP & FN & Sensitivity & specificity & PPV & NPV \\
\hline $\begin{array}{l}\text { Microscopic } \\
\text { examination }\end{array}$ & 116 & 19 & 66 & 0 & 31 & 38 & 100 & 100 & 68.04 \\
\hline Conventional PCR & 116 & 34 & 66 & 0 & 16 & 68 & 100 & 100 & 80.49 \\
\hline Real-time PCR (qPCR) & 116 & 50 & 66 & 0 & 0 & 100 & 100 & 100 & 100 \\
\hline $\begin{array}{l}\text { TP: True Positive, TN: True Negative, FP: False Positive, FN: False Negative, PPV: Positive Predictive } \\
\text { Value and NPV: Negative Predictive Value }\end{array}$ \\
\hline
\end{tabular}

Table 3

Estimation of the likelihood ratio (LR) for assessment and differentiation between microscopic examination, Conventional PCR, and qPCR for detection of Theileria equi amongst Equines.

\begin{tabular}{|lll|}
\hline Techniques & likelihood Ratio + ve (LR+) & likelihood Ratio -ve (LR-) \\
\hline Microscopic Examination & Infinite (Inf) & 0.62 \\
\hline Conventional PCR & Infinite (Inf) & 0.32 \\
\hline Real-time PCR (qPCR) & Infinite (Inf) & 0.00 \\
\hline
\end{tabular}

\section{Discussion}

Equine theileriosis is an important worldwide distributed tick-borne protozoan disease affecting equines that's can lead to serious health and economic impacts. Moreover, most infected animals showing no clinical manifestations and develop into asymptomatic carriers thus they can potentially spread the infection (Ueti et al., 2008). Due to low parasitemia in carrier animals, traditional methods (microscopic examination of blood smears) usually fail to precisely identify those carriers. For this reason, tests that depend on detecting genomic fingerprints of pathogens proved as more promising tools for the diagnosis of equine theileriosis (Malekifard et al., 2014).

This study aimed to evaluate the sensitivity of microscopic examination of a blood smear, conventional PCR, and Real-Time PCR (qPCR) in determining the prevalence of T. equi among equines from Giza Governorate, Egypt.

In the current study, the prevalence of $T$. equi by microscopic examination was $16.4 \%(19 / 116)$. This was in agreement with some former Egyptian studies that recorded 19.8\% (Radwan, 2009), 18 \% (Mahmoud et al., 2016), and 13.9 \% (Ibrahim et al., 2011). And lower than that recorded in Egypt by (Salib et al., 2013) 
who recorded 34\%, and (Farah et al., 2003) who recorded 38.9\%. The obtained results were higher than some recorded in other countries such as Abedi et al. (2015) in Iran 3.8\%, Malekifard et al. (2014) in Iran $6.25 \%$, and Sumbria et al. (2015) in India 4.17\%. Such difference may attribute to the vector activity in the study area, environmental conditions, and the disease stage -acute or chronic- at sampling (Mahdy et al., 2016).

According to the present study, the prevalence of $T$. equi by conventional PCR was $29.3 \%$ (34/116). This result was higher than those stated previously by (Ibrahim et al., 2011) in Egypt (26\%), (Davitkov et al., 2016) in Central Balkan (22.5\%), (Hosseini et al., 2016) in Iran (11.1\%), and (Guven et al., 2017) in Turkey (8.8\%) while it was lower than that's reported by (Mahmoud et al., 2016) in Egypt (36.4\%).

Concerning real-time PCR (qPCR), our results reported the prevalence of $T$. equi was $43.1 \%(50 / 116)$ which's agreed with (Alanazi et al., 2014) in Saudi Arabia (42\%). However, our result was lower than the result stated by (Bhoora et al., 2009) (80\%) in South Africa while it was higher than the result reported by (Jaffer et al., 2010) (36.2\%).

Current results declared that qPCR had the highest sensitivity (100\%) in detecting T. equi infection followed by conventional PCR (68\%) while microscopic examination of blood smears was the lowest sensitive technique (38\%). These results strongly agreed with previous results reported by (Ibrahim et al. 2011; Malekifard et al. 2014; Mohamed et al. 2016; Guven et al. 2017) who stated that molecular diagnostic tools had higher sensitivity in detecting $T$. equi compared to traditional methods.

According to the current study, the sensitivity of qPCR assay is $100 \%$ followed by conventional PCR $68 \%$ then Microscopical analysis $38 \%$ in the detection of T. equi. The NPVs of microscopical examination and conventional PCR were relatively low as $68.04 \%$ and $80.49 \%$, respectively when compared with qPCR that revealed $100 \%$ NPV. These results indicate $100 \%$ ability of qPCR to detect true negative when compared with the other two assays for diagnosis. So, it is recommended to combine PCR techniques with microscopic examination for studying the epidemiology of equine theileriosis, especially in carrier cases.

In the current study, results of likelihood Ratio for positive samples (LR+) were infinite for all three techniques while for negative samples (LR-) were $0.62,0.32$ and 0.00 for microscopic examination, conventional PCR and qPCR, respectively. The $L R+$ is a quantifiable proposal of the power of a positive outcome. The perfect diagnostic test would have an LR + equal to infinity (detecting all true positives, and producing no false positives), and the top test for sensing a disease is therefore the one with the highest LR+. While, the ideal diagnostic test would have an LR- equal to zero (producing no false negatives, but detecting all true negatives), and the topmost test for ruling out a disease is therefore the one with the lowest LR- (Thrusfield, 2005). According to this rule the qPCR technique is the best one in diagnosis of $T$. equi followed by conventional PCR then microscopic examination.

\section{Conclusion}


In conclusion, to conduct an epidemiological survey on equine theileriosis, it is highly recommended to associate conventional methods of diagnosis with molecular diagnostic tools due to their superior sensitivity and accuracy especially in subclinical and chronic phases of infection.

\section{Declarations}

\section{Compliance with ethical standards}

Ethical statement: All experimental conditions for animals were performed according to the guidelines approved by the Animal Care and Use Committee of Cairo University, Giza, Egypt.

Conflict of inters: Authors declared that there is no conflict of interest.

\section{References}

Abedi, V., Razmi, G., Seifi, H., Naghibi, A., 2015. Molecular detection of equine piroplasms in donkeys ( Equus asinus ) in North Khorasan province, Iran. Iranian Journal of Veterinary Research, Shiraz University 16, 202-204.

Alanazi, A. D., Said, A. E., Morin-Adeline, V., Alyousif, M. S., Šlapeta, J., 2014. Quantitative PCR detection of Theileria equi using laboratory workflows to detect asymptomatic persistently infected horses. Veterinary Parasitology, 206(3-4), 138-145.

Alhassan, A., Pumidonming, W., Okamura, M., Hirata, H., Battsetseg, B., Fujisaki, K., Yokoyama, N., Igarashi, I., 2005. Development of a single-round and multiplex PCR method for the simultaneous detection of Babesia caballi and Babesia equi in horse blood. Vet Parasitol. 129, 43-49.

Bhagwan, J., Kumar, A., Kumar, R., Goyal, L., Goel, P., Kumar, S., 2015. Molecular evidence of Theileria equi infection in Hyalomma anatolicum ticks infested on sero-positive Indian horses. Acta Parasitol. 60, 322329.

Bhoora, R., Quan, M., Franssen, L., Butler, C.M., Van der Kolk, J.H., Guthrie, A.J., Zweygarth, E., Jongejan, F., Collins, N.E., 2010. Development and evaluation of real-time PCR assays for the quantitative detection of Babesia caballi and Theileria equi

infections in horses from South Africa. Vet. Parasitol. 168, 201-211.

Davitkov, D., Vucicevic, M., Stevanovic, J., Krstic, V., Slijepcevic, D., Glavinic, U., Stanimirovic, Z., 2016. Molecular detection and prevalence of Theileria equi and Babesia caballi in horses of central Balkan. Acta Parasitol. 61, 337-342. 
Elseify, M.A., Helmy, N.M., Elhawary, N.M., Soliman, A.M., 2018. Using molecular techniques as an alternative tool for diagnosis and characterization of Theileria equi. Iraqi Journal of Veterinary Sciences. $32,1,5-11$.

Farah, A.W., Hegazy, N.A., Romany, M.M., Soliman, Y.A., 2003. Molecular detection of Babesia equi in infected and carrier horses by polymerase chain reaction. Egypt J Immunol. 10, 73-79.

Guven, E., Avcioglu, H., Deniz, A., Balkaya, I., Abay, U., Yavuz, S., Akyüz, M., 2017. Prevalence and molecular characterization of Theileria equi and Babesia caballi in jereed horses in Erzurum, Turkey. Acta Parasitologica 62, 207-213.

Hosseini, S. R., Taktaz-Hafshejani, T., Khamesipour, F., 2016. Molecular Detection of Theileria equi and Babesia caballi Infections in Horses by PCR Method in Iran. Kafkas Universitesi Veteriner Fakultesi Dergisi, 1-4.

Ibrahim, A.K., Gamil, I.S., Abd-El baky, A.A., Hussein, M.M., Tohamy, A.A., 2011 Comparative Molecular and Conventional Detection Methods of Babesia equi (B . Equi ) in Egyptian Equine. Glob Vet. 7, 201-210.

Jaffer, O., Abdishakur, F., Hakimuddin, F., Riya, A., Wernery, U., Schuster, R. K., 2009. A comparative study of serological tests and PCR for the diagnosis of equine piroplasmosis. Parasitology Research, 106(3), 709-713.

Kim, C., Blanco, L. B. C., Alhassan, A., Iseki, H., Yokoyama, N., Xuan, X., Igarashi, I. 2008. Diagnostic realtime PCR assay for the quantitative detection of Theileria equi from equine blood samples. Veterinary Parasitology 151, 158-163.

Levine, 1982. Veterinary Protozoology. lowa state Univerity Press.Ames.

Mahdy, O. A., Nassar, A. M., Mohamed, B. S., Mahmoud, M. S., 2016. Comparative Diagnosis Utilizing Molecular and Serological Techniques of Theileria equi Infection in Distinct Equine Populations in Egypt. International Journal of Chem Tech Research 9, 185-197.

Mahmoud, M.S., El-ezz, N.T.A., Abdel-shafy, S., Nassar, S.A., Namaky, A.H.E.I., Khalil, W.K.B., Knowles, D., Kappmeyer, L., Silva, M.G., Suarez, C.E., 2016. Assessment of Theileria equi and Babesia caballi infections in equine populations in Egypt by molecular, serological and hematological approaches. Parasites \& Vectors $9,1-10$.

Malekifard, F., Tavassoli, M., Yakhchali, M., Darvishzadeh, R., 2014. Detection of Theileria equi and Babesia caballi using microscopic and molecular methods in horses in suburb of Urmia , Iran. Vet Res Forum. 5, 129-133. 
Ozubek, S., Aktas, M., 2018. Genetic diversity and prevalence of piroplasm species in equids from Turkey. Comparative Immunology, Microbiology \& Infectious Diseases, 59, 47-51.

Radwan, A.M.M., 2009. An Investigation On Parasitic Infection In Equines. Banha Univ. Vet. Med. Dep. Parasitol. Thesis.

Salib, F.a., Youssef, R.R., Rizk, L.G., Said, S.F., 2013. Epidemiology, diagnosis and therapy of theileria equi infection in giza, egypt. Vet World. 6, 76-82.

Souza, E. A. R., Araujo, A. C., Pires, L., Freschi, C. R., Azevedo, S. S., Machado, R. Z., Horta, M. C., 2019. Serological detection and risk factors for equine piroplasmosis in the semiarid region of Pernambuco, Northeastern Brazil. The Brazilian Journal of Veterinary Parasitology, 28 (4), 685-691.

Sumbria, D., Singla, L., Amrita, S., Kaur, P., 2015. Detection of Theileria species infecting equine population in Punjab by $18 \mathrm{~S}$ rRNA PCR. Indian Journal of Animal Research, 0-6.

Thrusfield, M., 2005. Veterinary epidemiology, 3rd edn. Blackwell science publishing, New Jersey, pp 313317

Ueti, M., Palmer, G., Scoles, G., Kappmeyer, L., Knowles, D., 2008. Persistently infected horses are reservoirs for intrastadial tick-borne transmission of the apicomplexan parasite Babesia equi. Infect Immun. 76, 3525-3529.

\section{Figures}



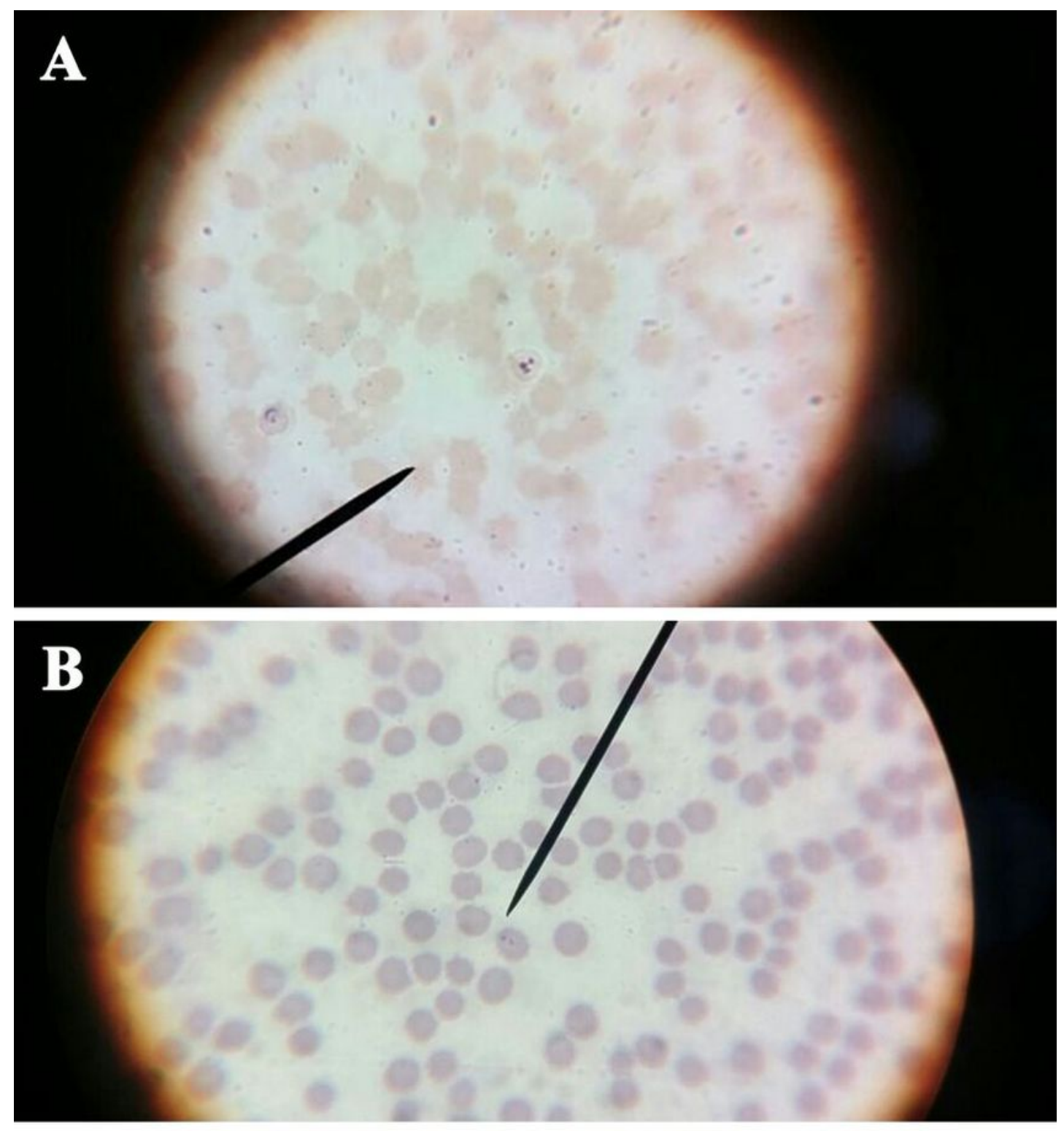

\section{C}

Figure 1

Microscopically stained blood smears showed different forms of Theileria equi merozoites (x100) A, B and $\mathrm{C}$. 


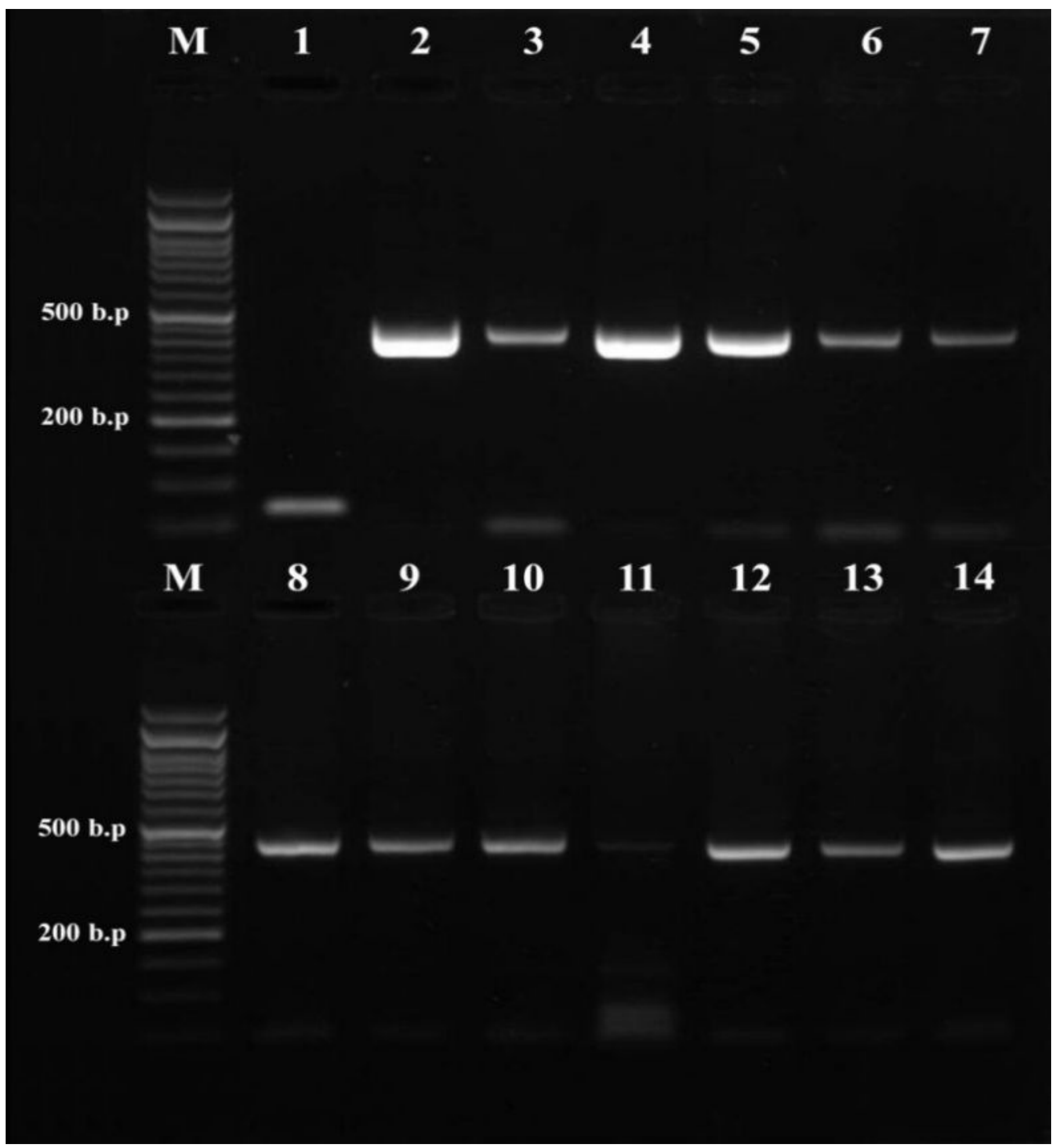

\section{Figure 2}

Results of Conventional PCR amplification for detection of T. equi at $392 \mathrm{bp}$ fractionated on 1.5\% agarose gel. Lane M: 50 bp DNA ladder, Lane 1: T. equi negative control, Lane 2: T. equi positive control, Lane 3-14 T. equi field positive samples. 


\section{Amplification Plots}

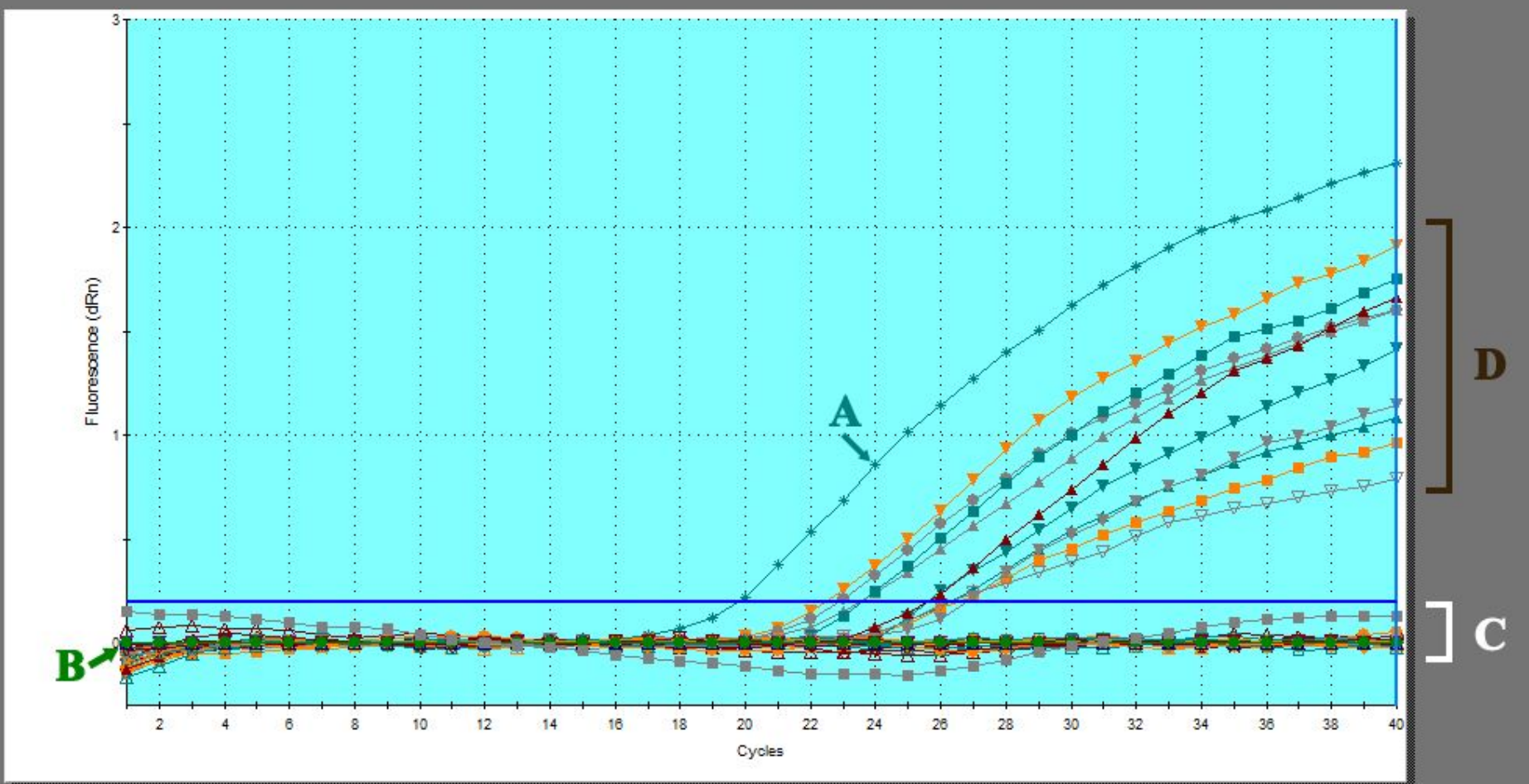

\section{Figure 3}

qPCR results for T. equi: A) positive control, B) negative control, C) negative field samples and D) positive field samples. 